\title{
Exploring the issues of digital outdoor architectural projections
}

\author{
Anthony Head \\ Bath School of Art and Design \\ Bath Spa University \\ Sion Hill, Bath, \\ United Kingdom \\ a.head@bathspa.ac.uk
}

\begin{abstract}
The last decade has seen a rise the popularity and achievability of large motion graphic outdoor projections. Mainly conducted by commercial companies due to the expense of hiring equipment these projections have utilised scanning and 3D modelling techniques to enchant and enthral audiences. But as the technologies behind projection comes down in price then it becomes in reach of a wider range of artists. The Illuminate Bath 2012 festival provided an opportunity to explore projection in a World Heritage city. On a relatively small budget we were able to try some new concepts in order to get people to view and experience the city in different way.
\end{abstract}

Digital projection mapping, interactivity, light festival, heritage, architecture, computer graphics

\section{INTRODUCTION}

Since the birth of cinema, the large projected image has captivated audiences, viewing films, in a group experience. Digital projectors with enough power to work outdoors on large buildings have developed over the last decade, creating images far larger than indoor cinema screens. This has led to an increasing number of companies and organisations creating 'shows' for public festivals and commercial customers.

Utilising computer graphics, scanning, photography and projection mapping techniques, an increasing amount of public art is being created at a monumental scale and is engaging audiences all over the world.

This paper provides an insight into the outdoor digital projection scene, and discusses the issues involved in creating outdoor projections based on the author's experience with running several projection events and festivals.

\section{TECHNICAL DEFINITIONS AND ISSUES}

\subsection{Projection definitions}

Outdoor projections that involve projecting onto buildings have several terms applied to them. These terms overlap, but help distinguish between different approaches to the technique of digital projection on buildings.

\subsubsection{Outdoor projection}

This is the general term meaning using projectors to play video or computer generated artworks onto a large canvas, usually a building. This can apply to non-digital techniques too, e.g. slide, or analogue projection.

\subsubsection{Architectural projection}

Architectural projection is the process of projecting onto architecture/buildings in a way that utilises the shape of the building. This implies having to overlay imagery after recording the shape of the building.

Recording the shape of a building can be done with photography, with the lens corrected to straighten lens distortion. It is best to take the photography from the position where the projector will be placed. The resulting photographic image is then used to overlay digital animations onto. When projected back on the building, the walls are transformed by an aligned animation that enhances the features of the building (walls, windows, doors, drain pipes etc).

\subsubsection{Projection mapping (also video mapping)}

A more accurate technique for recording the shape of a building is with $3 D$ scanning. This is known as 
projection mapping, scanning the contours and depths of a building to create a 3D model of it. Taking this 3D model into a 3D animation application enables the creation of 3D animations that appear to extrude or enhance the threedimensionality of the building, essentially creating optical illusions, and transforming the physicality of the building. A commonly seen idea from this is to project bricks onto the walls and then make them appear to move in and out. Because the animation is created in a 3D software package, light and shadow can be used to create extra depth to these animations. If the audience is in the right place, they get the full 3D effect, although if they are in the wrong place then the 3D perspective will be wrong.

\subsection{Contrast and brightness, day and night, light and dark}

The main technical issue with successful outdoor projection is the brightness and contrast of projection needed to overcome ambient light. In a cinema, the room can be made completely dark. The darker the environment, then the darker 'black' appears to be, hence the better the contrast for the image. From my own experience, a pale projection is not very impressive, and a very pale projection (low contrast, same brightness as the ambient light) is barely visible.

The unit in which projector brightness is measured is the ANSI (American National Standard Institute) lumen. A typical indoor office projector will measure between 1,000 and 2,000 ANSI lumens.

\subsubsection{Daylight outdoor projection}

When using projectors in indoor situations, where blinds can be drawn, and lights switched off, projectors don't need to be very powerful. However, outdoors, if one is projecting a large image on to a wall when the sun is out, then a satisfactory result is unlikely. Direct sunlight measures 100,000 lumens over a $1 \mathrm{~m}^{2}$ surface (Wikipedia - Sunlight 2012) and currently the brightest projector measures 43,000 lumens over a $4 \mathrm{~m}^{2}$ area (Barco 2012), equivalent to approximately 10,000 lumens at $1 \mathrm{~m}^{2}$, or one tenth of the brightness.

Reflective backdrops (cinema screens) can be used to create a high contrast projection surface, but this is not the point of architectural projection mapping (transforming the architecture), and even if one uses such reflective backdrops, the darker the venue is, the better the outcome. Also, outdoor projection should not be confused with giant LED screens, often used in stadiums.

No current projector can compete with direct sunlight for large scale projections.

\subsubsection{Nighttime outdoor projections}

Most projection events require full darkness. It is easy to underestimate just how much darkness is needed. But even at night there are still issues with light. Outdoors settings, such as towns and cities, receive a great deal of light at night time from streetlights, shops, house lights, and cars. Streetlights are the biggest problem for outdoor projection in urban environments in terms of competing for brightness. Obviously they are designed to light up the street, and need to be turned off for duration of a projection performance.

If the projection is in a commercial area then the likelihood is that shops will have lights on at night. This too can make a dramatic difference to projection.

All ambient light interferes with the strength of the projection. To project in an environment with a high level of ambient light requires the most powerful projectors, which are expensive, and even these might not be able to compensate for ambient light. If one is setting up a projection event, every effort should be made to reduce ambient light, which means choosing the right location and usually working with a local Council to get the street lights turned off.

This may all sound like common sense, but it is only when one sees a projection emerge out of a setting sun, and into night time, that one appreciates just how important low, or better still, no ambient light is. But that leads on to health and safety issues with the audiences, which is another matter.

\subsection{Projector types}

The advance of projection technology over the last decade has enabled the possibility of digital projection to take place at a large scale. Powerful projectors are very expensive to buy, and hence expensive to hire. A high quality projector this cost in the region of $£ 1,000$ to $£ 7,500$ a week to hire, depending on the projector and the company loaning it out.

Modern projectors used for outdoor digital projection fall into two categories, LCD and DLP. There are older projection technologies, for example, three colour CRT projectors, but these are not easily portable. LED projectors are coming on to the market but they aren't yet powerful enough for large outdoor projection.

The three main companies who create powerful outdoor projectors are Barco, Christie and Sanyo. Other companies make projectors, but they tend to concentrate on the office, and small venue market. 


\subsubsection{LCD (Liquid Crystal Display) projectors}

These projectors were initially conceived in 1968 by inventor Gene Dolgoff (Wikipedia 2012), but it was not until 1988 that they were launched to the world market, following a long period of development.

Current LCD projectors range up to 15,000 lumens, (e.g. Sanyo XF47) which is sufficient for outdoor projection (depending on the scale of the surface). They are portable, but bulky, requiring 3 to 4 people to carry and position them.

\subsubsection{DLP (Digital Light Processing) projectors}

DLP projectors have a reputation for being higher in contrast than LCD, although this is not actually proven. However, they are available in higher lumens options, the brightest being the Barco DP2K-32B (Barco 2012). This 33,000 lumens projector was measured at 43,000 lumens. Christie also now produce a 32,500 lumens projector.

\subsection{3 $H D$ and 3D projectors}

The cost to hire projectors is not just dependent on the brightness, but also the resolution. HD resolution, $1920 \times 1080$ pixels is becoming more common amongst projectors. With the main companies creating projectors capable of HD resolutions. This means that the projected images on buildings can have a greater level of detail. This is more important as the images get larger.

\subsection{Multiple projectors}

The above issues and specifications imply that only one projector can be used for any event. However, this is not the only necessary approach.

\subsubsection{Media servers}

By using media server (a computer controlling display computers with specialist software) it is possible to tile multiple projectors together to create a larger image that still has sufficient brightness. This is a technique that is often used to create very large projections, for example by tiling projectors in $3 \times 2$ formation. The media servers also help overlay the edge of each image, vignetting the images so that one image smoothly blends into the next.

\subsubsection{Daisy chaining}

Another technique, used to increase the brightness of a projection, is to "daisy chain" two projectors together. This means connecting the output from one projector into the input of a duplicate projector. The two projectors are then angled in exactly the same position in order to double-up the image. This simple technique can make two cheaper 10k lumens projectors equivalent to a $20 \mathrm{k}$ lumens projector. The main reason to do this is cost, as often the lower powered projectors are significantly cheaper to hire.

\subsection{Alternative projection technique - PIGI projectors}

PIGI ("pee-gee") is a French acronym meaning "giant image projector with computer control" (Electric Canvas 2012). PIGI projectors are actually brighter than digital projectors and hence can be used to cover larger surfaces with fewer projectors. They are different to digital projectors in that they use large scrollable film. However, their computercontrolled nature means that relatively sophisticated scrolling effects can be achieved. However, this method is not as versatile as using digital projectors and computer video graphics.

\section{PRACTITIONERS OF PROJECTION}

Creating digitally projected events is a team effort, ultimately it is the content that matters, not the technology that has been used to create it. There are not many companies that work in this arena, but the more events that happen means the more that people want to get involved in this activity. Below is a list of a few organisations that have been successfully producing projection-mapped artworks.

AntiVJ (AntiVJ 2012) is a relatively recent European collective of artists including Joanie LeMercier, which formally began in 2008. Coming out of the VJ (Video Jockey) scene, with small club based performances, they now specialise in 3D projection mapping and coded video to create illusion-based and spatially provoking pieces. Often transforming architecture by playing with scale and depth, or revealing the inner workings of building, they have produced works in many European cities.

Seeper (Seeper 2012) is a company formed by Evan Grant in 1998, has been creating graphical and interactive experiences internationally. Their work has explored large outdoor projection using pre-rendered $3 \mathrm{D}$ and video. They have also explored real-time computer graphics (as opposed to pre-rendered) and interactivity using Xbox Kinect and multi-touch surfaces (the latter not for large outdoor projection however). Using Kinect in a projection situation enables members of the audience to not only to watch, but also to participate in a full body way, albeit only one or two people at a time. This adds a higher level of engagement to their work.

Ross Ashton, of The Projection Studio (The Projection Studio 2012), has been working with digital projection since 1992. He creates work of a historical and narrative nature that draws upon the locations in which his projections are set. As the technology has improved, so has the scale of 
Ashton's work. He is a regular creator of work for various 'son et lumieres' - sound and light performances. His work has been mainly shown using PIGI projectors, this leads it to have quite a distinctive scrolling animated style.

In November 2011, ETC Russia (ETC Russia 2012) worked with David Atkins Enterprises (DAE) to create the Guinness World Record for the largest video-mapped projection. This involved over 80 Christie video projectors projecting a 30 minute animated show on the $200 \mathrm{~m}$ wide Moscow State University. (ETC Russia 2012)

\section{LIGHT FESTIVALS AND EVENTS}

Projections are often created as one off events in themselves. This might be an event to mark a launch of a commercial product, or celebrate a commercial occasion. For example, the Russian company Alfa Bank, celebrating its 20th anniversary, sponsored the world record projection mentioned above (Christie 2012). Commercial sponsorship was possible because projection events are big and impressive, and can help the client be noticed. But, as mentioned earlier, they can be expensive too, meaning they are not easily within the reach of the average artist.

The other vehicle for projection-based art is festivals, often supported by City Councils with art budgets. Festivals of Light are not new, and appear all over the world. For example, the Hindi festival Diwali is a festival of light. It is the inclusion of digital projection that is transforming these festivals, with animations and mapped imagery.

UK based light or illumination festivals have attracted funding from Arts Council and other regional arts funders. Some examples are below.

Durham's Lumiere (Lumiere 2012) hails itself as the UK's largest light festival, and has run in 2009 and 2011. It's organised by arts curators, Artichoke and featured many artists and artworks from projections to installations.

Illuminating York (Illuminating York 2012) has run for seven years, and is organised by the York Council and local businesses, and Arts Council sponsorship. Like Lumiere it features a range of artworks projected and other light.

Illuminate Bath (Illuminate Bath 2012) as had two festivals, 2010 and 2012. This is the festival that I am Creative Director of and I will explain some of the particular projection ideas that we have pursued in the next section.

\section{ILLUMINATE BATH}

Illuminate Bath came about as a result of funding from a Cultural Olympic project called RELAYS, which provided the funding for logistics and enabled Bath Spa University to create the festival, with support from our local council, Bath and North East Somerset.

\subsection{Illuminate Bath 2010}

Illuminate Bath 2010 festival was our first attempt in the Light Festival scene. It featured mainly student artworks, installations as well as artworks by Bath Spa University artist/lecturers. The festival ran over 14 days and had audience figures of about 40,000 people. (Illuminate Bath 2010)

The festival did include some projections, using 6,500 lumens projectors, but these were not big enough to fill up walls. On the final night we used two, more powerful projectors. These would have been suitable, except that it was not possible to turn the streetlights off (our location was not Council property). This meant that one projection was barely visible. This was very frustrating, but a lesson was learned.

Overall, we (myself and the festival producer Arilda Tymko) learnt a lot from organising the festival, including logistics and developed a relationship with the City Council.

\subsection{Illuminate Bath 2012}

For the second festival, a bigger budget was available. It was also decided to condense the festival into four days. This meant that it was possible to hire projectors for the period of a week, which was more economical. We also condensed the area in which the festival was shown, focussing on the city centre radius of a quarter mile. The desired effect here was to enhance the atmosphere of the festival and give it a real visible presence.

We achieved our goals and gained 35,000 visitors over the four evenings showing a number of artworks, some installations, and some large projections.

The festival was deliberately given a theme of 'interactivity'. A theme is useful, but it is often best to allow it to be interpreted. However, what this led to was a push into different areas for projection.

\section{PROJECTION AND INTERACTIVITY}

\subsection{Live illustration}

Live illustration was an interpretation of the 'interactive' theme - human to computer interaction. 
We involved the Creative Federation (Creative Federation 2012), a group of Illustrators and Animators, and Tim Vyner an illustrator from Bath Spa University, in an opportunity to make drawings on the nights on a 40' wide projection on the side of the world famous Roman Baths building. This wasn't so much about mapping, but in engaging the audience with a live canvas. (Figures 1 and 2)

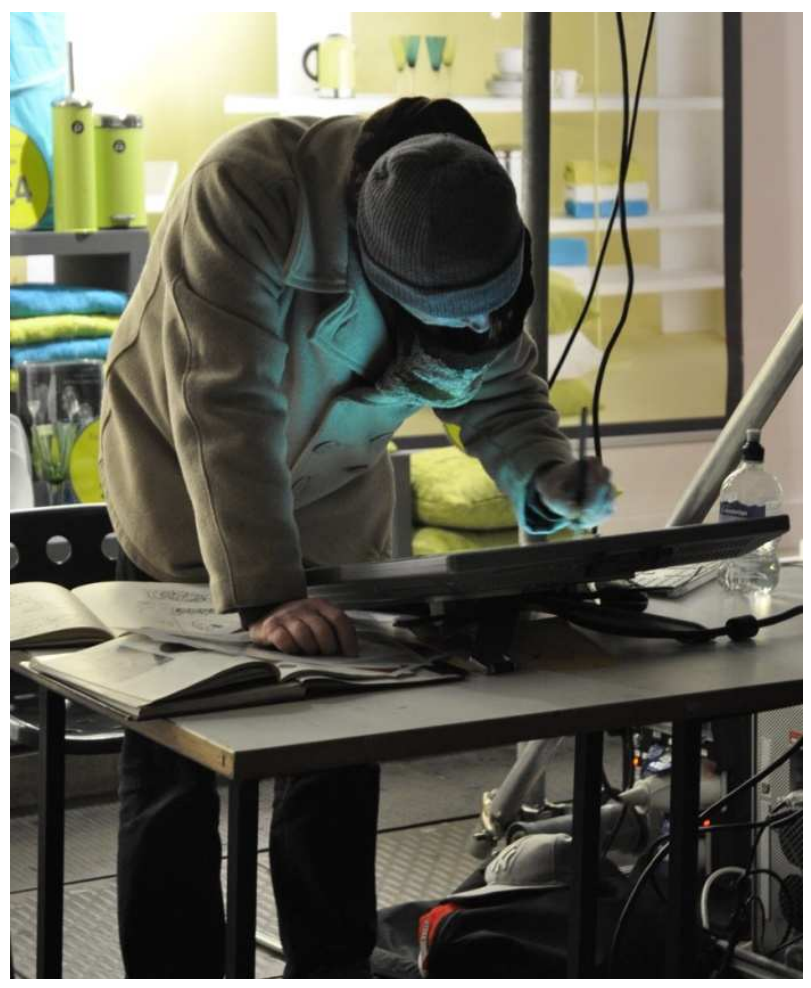

Figure 1 Tim Vyner drawing at Illuminate Bath 2012

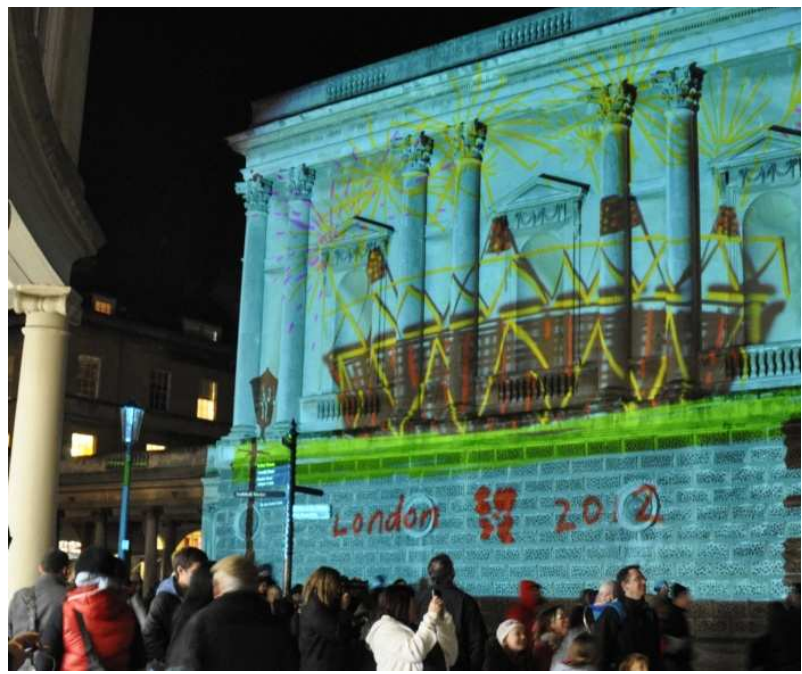

Figure 2 Tim Vyner's Olympic themed illustration

We even merged this drawing concept with poets performing poems whilst Simon Spilsbury, of The Creative Federation drew images that related to the poems. (Figures 3 and 4)

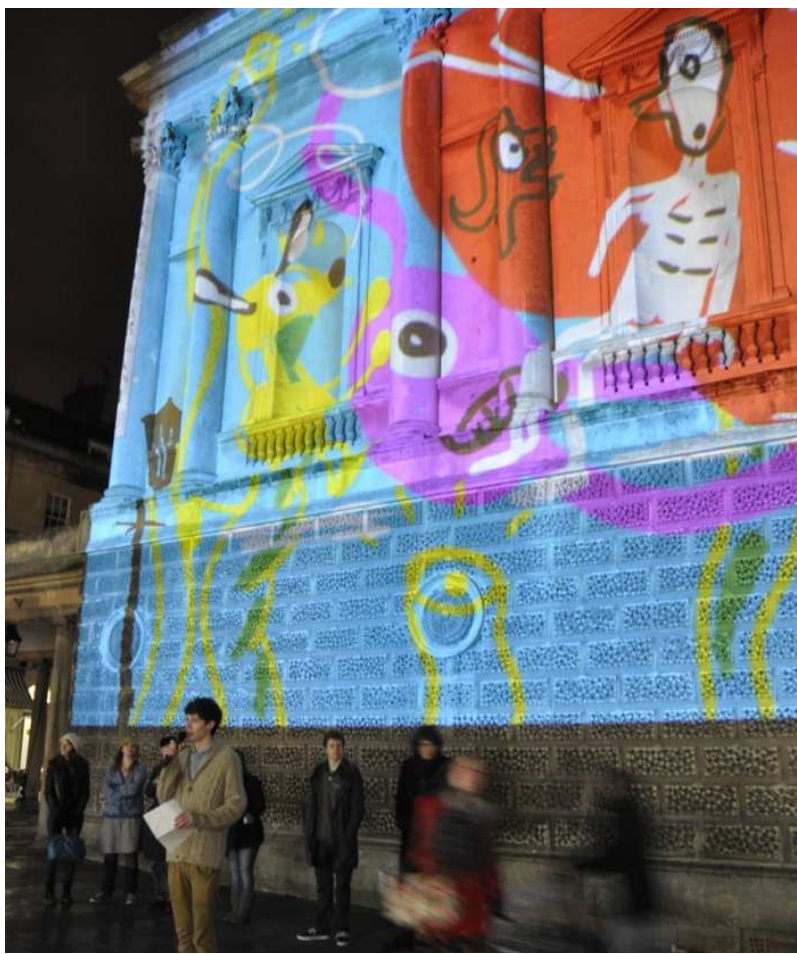

Figure 3 Poetry performance to the illustration of Simon Spilsbury of the Creative Federation

The drawing was created using a large Wacom tablet, with built in screen. It was super-imposed on a photograph of the wall on the screen and then the illustrators drew over it in Adobe PhotoShop. This allowed them to utilise the shape of the building, if they wished to, although this was not the main interest of the illustrators. Utilising the building's shape is not always necessary to create impact.

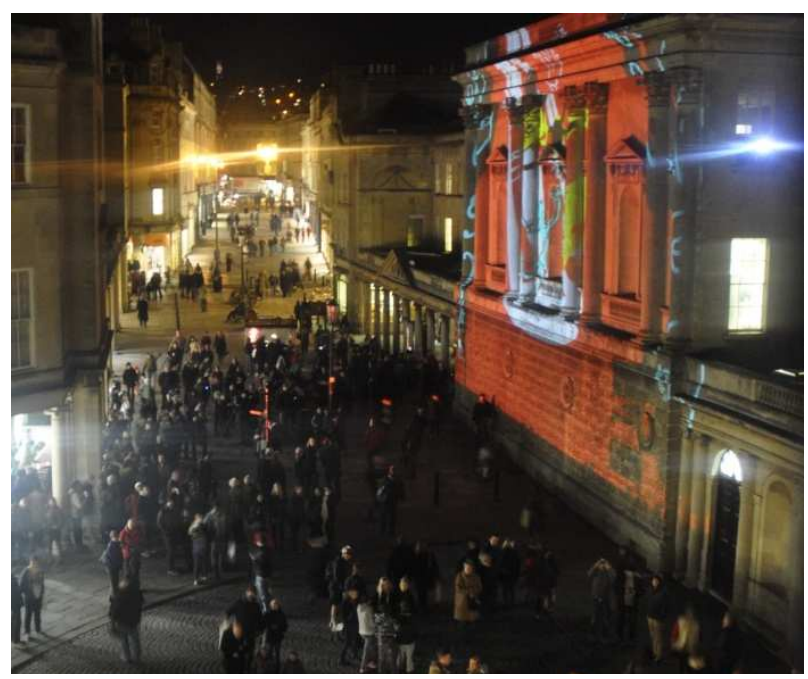

Figure 4 Simon Spilsbury's illustration and the crowd towards the end of the night.

At a later event, the XMediaLab conference XML Bath 2012 (XMediaLab 2012) iPads running Brushes (a drawing application) was used to allow the illustrators to draw freely whilst roaming the location of Georgian Assembly Rooms in Bath 
(wirelessly). We placed three 6,500 lumens projectors next to each other to create a 40 feet canvas. This was deliberately not aligned, in order to make the space informal. The quick drawing nature of the illustrators meant that the image on the walls constantly evolved. One interesting aspect of the Brushes software is that one can replay the drawing sequence as an animation. This allowed the illustrators to create instant animations.

\subsection{Computational projection}

The next form of interactivity for projections was computational. In one artwork, Attracted to Light by myself and Bob Fearns, (Head 2012) we mapped recorded video sequences to ten windows of a building. The recordings were silhouettes of people, which played for around 30 seconds and then turn off, as if a light was being turned off. (Figure 5)

The computational interactivity (computer computer) was a number of moths that flew across the wall and gathered around a window if the light was switched on, and then dispersed when it switched off. The random flying nature of the moths and the randomness of the silhouette films turning on and off meant that this projection never repeated, and so wasn't restricted to a duration and repeat.

This kind of work has a subtlety to it that differentiates it from performances, in the sense that there is a constant pace.

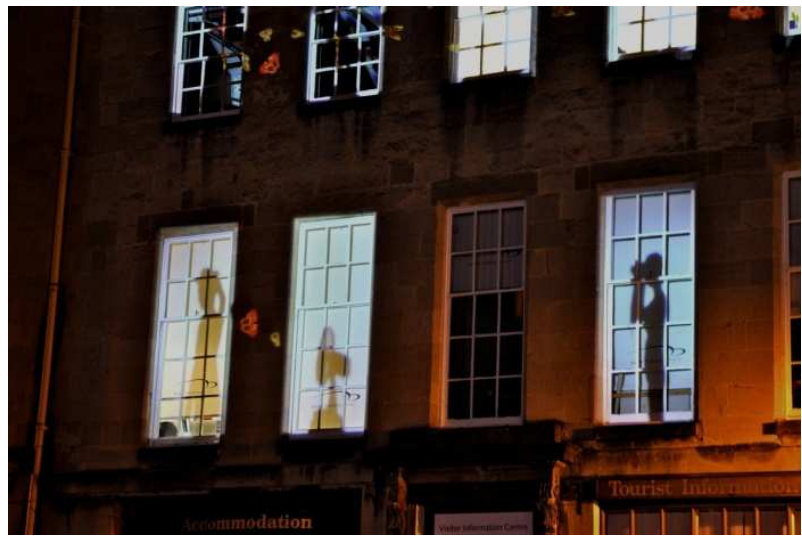

Figure 5 'Attracted to Light' computer controlled moths and silhouette films by Anthony Head and Bob Fearns

\subsection{Projection mapped and cinematic}

We had one wall in the street that featured a number of films and animation sequences. Some were mapped and others not. This constant rotation of films meant that many different people could participate in the screening (most were student animations).

The few animations that were mapped were rhythmic and responded to sounds or music. These were not interactive, but the potential is demonstrable. (Figure 6).

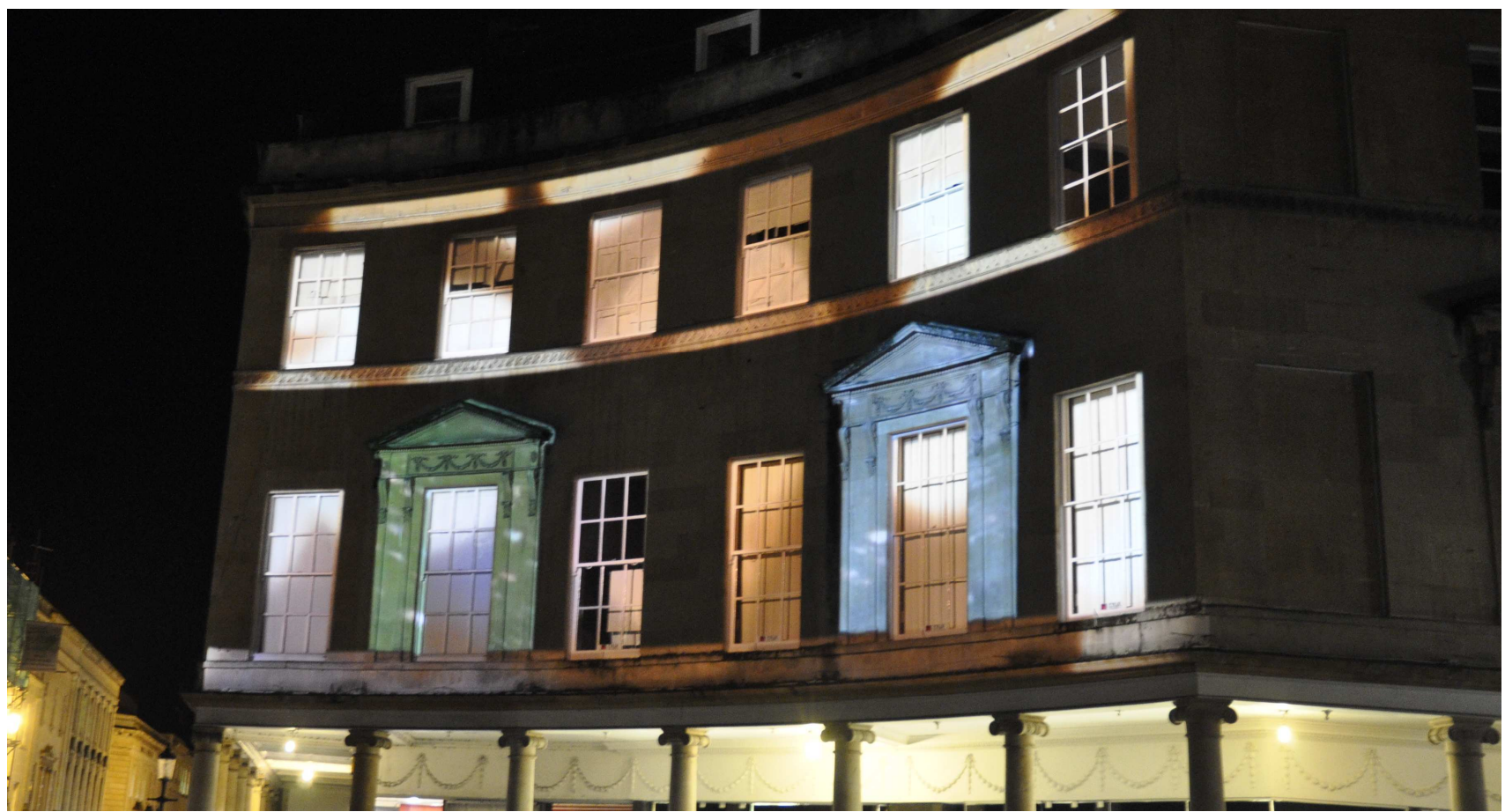

Figure 6 Rhythmic projection mapped animation by Anthony Head 


\subsection{Input interactivity}

Although not displayed on a wall during the festival, we did create a projected game that involved the drawings of 50 school children, animated and turned into a 'Heads, bodies, legs' game where the audience members pressed three buttons to change the images (human - computer interactivity). We also featured user input in the Clockwork City project by Greyworld (Greyword 2012). Greyworld's keys were used to switch on projections created by students, including one that was mapped onto a phone box. This was an interesting extension of architecture to street furniture (Figure 8).

The idea of user input interactivity featured in a previous event that was projection-mapped in February 2011. With the help of Bath Spa University students, I created a 30' high pinball game, the background of which matched to the building shape. The game was created for Comic Relief and members of the public could control the game by standing on pressure pads to operate the paddles. (Figure 7)

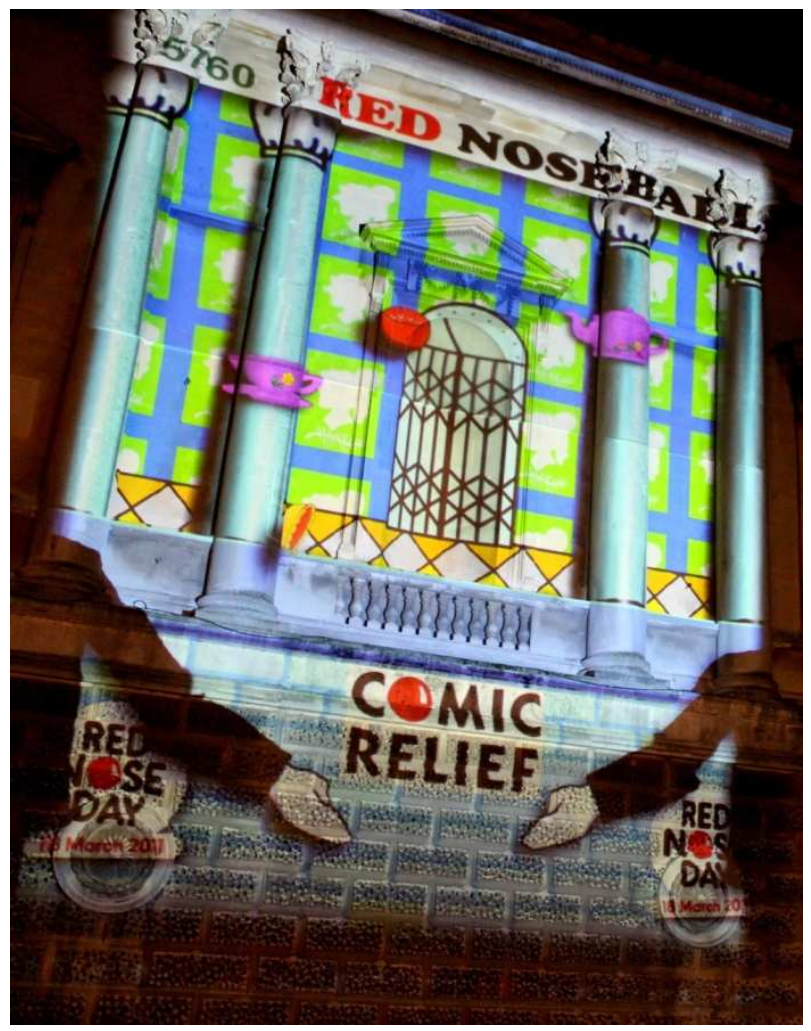

Figure 7 'Comic Relief 2011 pinball game' an interactive projection by Anthony Head and Bath Spa University students

\section{CONCLUSION}

Throughout this paper I have looked at the ways in which projectors have been used so far to transform outdoor architecture with animation and video. Admittedly, the works are not often concerned with the architecture itself, but it is possible to use either the shape of the building, building itself, or the local history as a starting point for a film.

A few years ago, the showing of projections with buildings crumbling, exploding was novel, impressive and technically challenging. The more experience that people build up in this area, then the more people will push the boundaries, and the more audiences will expect surprises. But the exploding brick, toppling building, is becoming a cliché, so artists and designers need to look to more imaginative ways to explore this medium.

I believe that there is further scope for the development of interactive experiences mixed with architectural projection. The conversion of giant projections to respond visually to music, controlled by the crowd has not been explored much yet, as it requires the use of real-time graphics, which the media servers aren't intended for.

Audience interaction with public artworks is not a simple concept. It is important that the audience realises that it is influencing the artwork, otherwise the piece doesn't need to have human-computer interaction.

\section{ACKNOWLEDGEMENTS}

Illuminate Bath was made possible by funding from RELAYS, the in-kind support of Bath Spa University, the in-kind, logistical support and cooperation of Bath and North East Somerset Council, the cooperation of local businesses.

\section{REFERENCES}

AntiVJ (2012), http://www.antivj.com (retrieved 3 April 2012)

Barco (2012), "Barco's DP2K-32B" http://www.barco.com/en/thebrightest (retrieved 3 April 2012)

Christie (2012), "Alfa Bank 4D" http://vimeo.com/34022569 (retrieved 3 April 2012)

Head, A (2012), "Attracted to Light" http://www.illuminatebath.org/2012/02/attracted-tolight-film/ (retrieved 3 April 2012)

Illuminate Bath (2010), http://www.illuminatebath.org/2010 (retrieved 3 April 2012)

Electric Canvas (2012), http://www.theelectriccanvas.com.au/services/pigiprojection (retrieved 3 April 2012) 
ETC Russia (2012) http://www.etc-russia.ru/en/ (retrieved 3 April 2012)

Greyworld (2012) http://www.greyworld.org (retrieved 3 April 2012)

Illuminate Bath (2012),

http://www.illuminatebath.org (retrieved 3 April 2012)

Illuminating York (2012),

http://illuminatingyork.org.uk (retrieved 3 April 2012)

Lumiere (2012), http://www.lumieredurham.co.uk (retrieved 3 April 2012)

Seeper (2012), http://www.seeper.com (retrieved 3 April 2012)

The Creative Federation (2012)

http://www.thecreativefederation.co.uk (retrieved 3 April 2012)

The Projection Studio (2012),

http://www.theprojectionstudio.com (retrieved 3 April 2012)

Wikipedia (2012), "Sunlight"

http://en.wikipedia.org/wiki/Sunlight (retrieved 3 April 2012)

Wikipedia (2012), "LCD projector"

http://en.wikipedia.org/wiki/LCD projector

(retrieved 3 April 2012)

XMediaLab (2012),

http://www.xmedialab.com/events/2012/xml-bath-

2012-digital-entertainment/ (retrieved 3 April 2012)

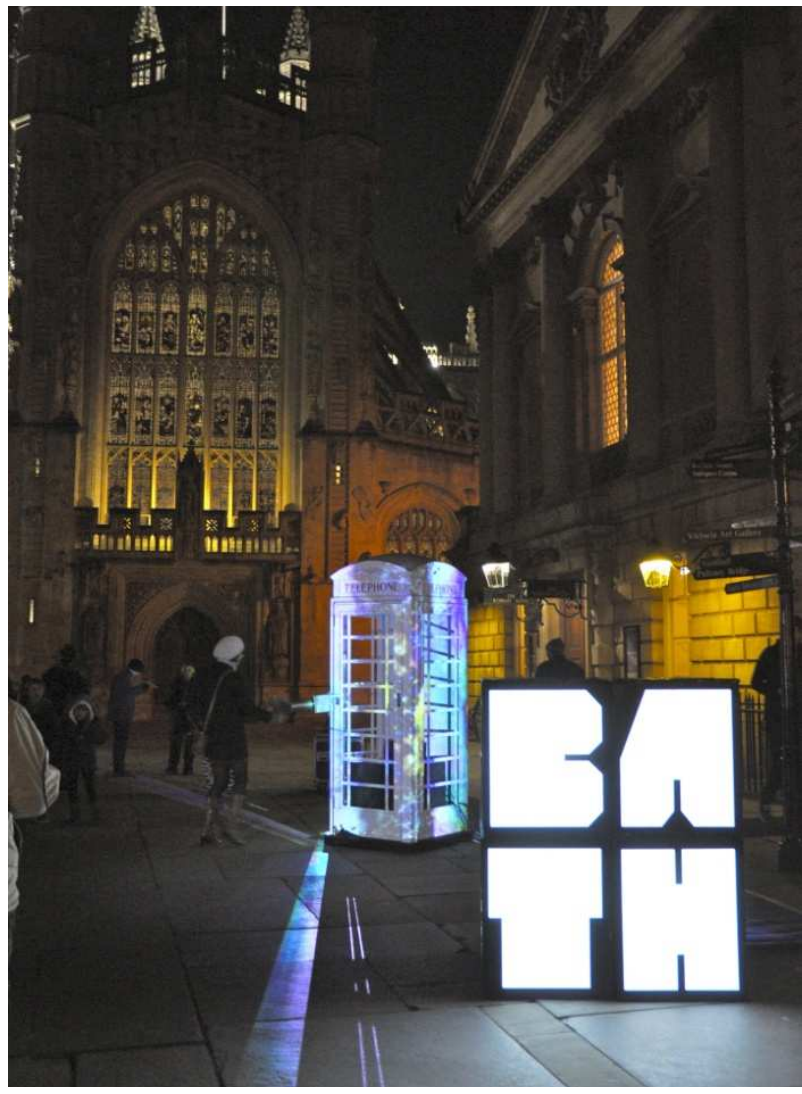

Figure 8 Showing the Phone Box mapped projection, by students Pinn Bunyapana and Tom Wells, operated by a 'Clockwork City' key by Greyworld, and also a BATH illuminated sign designed by Ben Hamilton (www.beninternational.org) created by student Alex Cotterell. 